\title{
Staphylococcus aureus Proteases Degrade Lung Surfactant Protein A Potentially Impairing Innate Immunity of the Lung
}

\author{
Tomasz Kantyka ${ }^{a} \quad$ Krzysztof Pyrc ${ }^{a, c}$ Milosz Gruca ${ }^{a} \quad J a n$ Smagur ${ }^{a}$ Karolina Plaza ${ }^{a}$ \\ Krzysztof Guzik $^{b}$ Slawomir Zeglen ${ }^{d}$ Marek Ochman ${ }^{d} \quad$ Jan Potempa ${ }^{a, e}$ \\ Departments of a Microbiology and ${ }^{\mathrm{b}}$ Immunology, Faculty of Biochemistry, Biophysics and Biotechnology, and \\ 'Malopolska Centre of Biotechnology, Jagiellonian University, Krakow, and d Department of Cardiac Surgery and

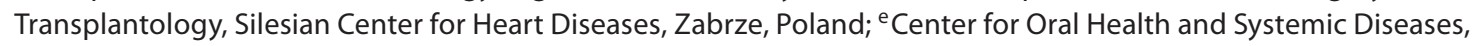 \\ School of Dentistry, University of Louisville, Louisville, Ky., USA
}

\section{Key Words}

Bacteriology $\cdot$ Host defense $\cdot$ Proteinases

\begin{abstract}
The pulmonary surfactant is a complex mixture of lipids and proteins that is important for respiratory lung functions, which also provides the first line of innate immune defense. Pulmonary surfactant protein-A (SP-A) is a major surfactant component with immune functions with importance during Staphylococcus aureus infections that has been demonstrated in numerous studies. The current study showed that $S$. aureus can efficiently cleave the SP-A protein using its arsenal of proteolytic enzymes. This degradation appears to be mediated by cysteine proteases, in particular staphopain A (ScpA). The staphopain-mediated proteolysis of SP-A resulted in a decrease or complete abolishment of SP-A biological activity, including the promotion of $S$. aureus phagocytosis by neutrophils, aggregation of Gram-negative bacteria and bacterial cell adherence to epithelium. Significantly, ScpA has also efficiently degraded SP-A in complete bronchi-alveolar lavage fluid from human lungs. This indicates that staphopain activity in the lungs is resistant to protease inhibitors, thus suggesting that SP-A can be cleaved in vivo.
\end{abstract}

Collectively, this study showed that the $S$. aureus protease ScpA is an important virulence factor that may impair innate immunity of the lungs.

Copyright $\odot 2012$ S. Karger AG, Basel

\section{Introduction}

The pulmonary surfactant is a complex mixture of lipids and proteins that forms a thin film at the air-liquid interface of the lung alveoli, which is essential for respiratory functions and gas exchange [1]. Apart from its function in the gas exchange process, the surfactant also provides the first line of innate immune defense in the lungs. Its mechanism of action relies on the enhancement of microbial neutralization and the clearance of microorganisms, as well as attenuation of potentially harmful inflammatory responses [2-9]. The major components responsible for this immune defense function are the pulmonary surfactant proteins, i.e. SP-A, SP-B, SP-C and SPD. SP-A and SP-D, which are large proteins structurally

Tomasz Kantyka and Krzysztof Pyrc contributed equally to this work.

\section{KARGER}

Fax +41613061234

E-Mail karger@karger.ch

www.karger.com (c) 2012 S. Karger AG, Basel

$1662-811 X / 13 / 0053-0251 \$ 38.00 / 0$

Accessible online at:

www.karger.com/jin
Dr. Krzysztof Pyrc

Department of Microbiology, Faculty of Biochemistry

Biophysics and Biotechnology, Jagiellonian University

Gronostajowa 7, PL-30-387 Krakow (Poland)

E-Mailk.a.pyrc@uj.edu.pl 
and functionally related to hydrophilic proteins that belong to a subgroup of mammalian lectins known as 'collectins' (together with mannose-binding lectin), whereas SP-B and SP-C are small hydrophobic proteins [10].

SP-A is the major constituent of the pulmonary surfactant where it is involved in the organization of large surfactant phospholipid aggregates that line the alveolar surface and acts as an opsonin for colonizing bacteria [1113]. SP-A is incorporated in the tubular myelin fraction of the pulmonary surfactant that covers the alveolar lining fluid of the distal airway epithelium, which can reorganize and expose SP-A, allowing it to bind to pathogens $[14,15]$. As a consequence, immune cells present in the alveolum of the lung, such as macrophages, neutrophils and monocytes, can easily recognize pathogens via binding to SP-A-opsonized bacteria. SP-A binds pathogens by a C-terminal lectin-like domain and its collagen-like $\mathrm{N}$ terminal domain is involved in the oligomerization of SP-A molecules [16]. SP-A aggregates in the presence of $\mathrm{Ca}^{2+}$ ions, which may facilitate its binding to multiple epitopes exposed on bacterial surfaces [17]. The importance of SP-A in innate defense mechanisms has been demonstrated in vitro and in vivo. SP-A-deficient mice are highly susceptible to viral and bacterial infections caused by Staphylococcus aureus, group B streptococcus, Haemophilus influenzae, Pseudomonas aeruginosa, Pneumocystis jiroveci and the respiratory syncytial virus [2, 18-23].

S. aureus is a Gram-positive bacterium that persistently colonizes $\sim 20 \%$ of the human population [24]. This high prevalence is reflected in the role of $S$. aureus as an important pathogen responsible for various illnesses in humans and animals worldwide, including respiratory tract, musculoskeletal, bloodstream, skin and soft tissue infections [25-27]. Extracellular proteases produced by S. aureus appear to be essential for successful infections. The most abundant secreted enzymes are staphopains A (ScpA) and B (cysteine proteases), V8 protease (serine protease) and aureolysin (metalloprotease) which activate themselves in a proteolytic cascade [28]. These proteases interact with the host tissue components in vitro to modulate host defense mechanisms $[29,30]$ and likely increase bacterial survival [31-38].

Previous reports demonstrate that the SP-A protein is also important for S. aureus clearance. Specifically, SP-A binds the extracellular adhesion protein on the staphylococcal surface and links the complex to SP-A receptor 210 (SP-R210) and scavenger class A receptors (SR-A) on macrophages. In this way SP-A facilitates $S$. aureus clearance from the infected lungs by phagocytosis [23].
The current study investigated the effect of $S$. aureus extracellular proteases, including ScpA, staphopain B, V8 protease and aureolysin, on the integrity and function of SP-A. We found that among tested staphylococcal proteases ScpA most efficiently degraded SP-A and abolished the antibacterial activity of this surfactant protein.

\section{Materials and Methods}

\section{Cells and Bacteria}

Polymorphonuclear cells (neutrophils) were isolated from erythrosediments by blood sedimentation in $1 \%$ polyvinyl alcohol solution (Merck) for $20 \mathrm{~min}$ at room temperature. Neutrophils were collected from the upper layer and contaminating erythrocytes were lysed by a 20 -second incubation in demineralized water. Pappenheim staining indicated that isolated cells were at least $90 \%$ homogenous. Neutrophils were used immediately after harvesting. Human lung carcinoma A549 cells (ATTC CCL185) were cultured in D-MEM media (PAA) supplemented with $10 \%$ of FBS and non-essential amino acids (PAA).

Well-characterized S. aureus strains: Newman (human isolate; kindly provided by T.J. Foster), LAC (Los Angeles County; community-associated, methicillin-resistant strain) and 8325-4 (laboratory strain; high expression of proteolytic enzymes), a kind gift from Lindsey Shaw, were cultured in tryptic soy broth (TSB) liquid medium (Sigma-Aldrich). Salmonella spp. (kindly granted by Dr. Kinga Wójcik) was cultured in Luria-broth liquid media (Sigma-Aldrich). In all cases, the bacteria concentration was assessed by optical density measurements in liquid media $\left(\mathrm{OD}_{600}\right.$ or $\left.\mathrm{OD}_{660}\right)$ or by scoring the number of colonies on solid media (colony-forming unit number; $\mathrm{cfu}$ ).

\section{Isolation of S. aureus Extracellular Proteases}

Both staphopains and V8 protease were purified from the $S$. aureus BC10 V8 strain, as described previously [39]. Staphopain $B$ and V8 protease were purified on a Q Sepharose FF (GE Healthcare) column at $\mathrm{pH}$ 5.5. Fractions containing proteolytic activity were further purified on a Phenyl Sepharose High Performance column (GE Healthcare). ScpA was purified using CM Sepharose FF (Amersham-Pharmacia) chromatography followed by highresolution ion exchange chromatography on a MonoS HR 5/5 column (GE Healthcare).

Aureolysin was purified on a DEAE-Sepharose column (GE Healthcare). Resulting fractions exhibiting EDTA-sensitive proteolytic activity were pooled and dialyzed against $50 \mathrm{~mm}$ Tris- $\mathrm{HCl}$ $\mathrm{pH}$ 7.6. All proteases were aliquoted and stored at $-20^{\circ} \mathrm{C}$.

Enzymatic activity of ScpA, staphopain B in purified samples was determined by titration using azocol substrate with macroglobulin and staphostatin B, respectively. Activities of aureolysin and $\mathrm{V} 8$ protease were assumed to be $100 \%$.

\section{Proteolytic Processing of Surfactant Protein A}

Cysteine proteases (ScpA and staphopain B) were activated by incubation in buffer containing $2 \mathrm{mM}$ DTT, $50 \mathrm{~mm}$ Tris- $\mathrm{HCl}, \mathrm{pH}$ 7.6 and $5 \mathrm{mM}$ EDTA. SP-A was incubated in the presence of bacterial proteases at $37^{\circ} \mathrm{C}$ for $90 \mathrm{~min}$. Furthermore, samples containing SP-A were mixed with SDS-PAGE sample buffer, separated on 
polyacrylamide gel and electrotransferred onto a nitrocellulose membrane for Western blot analysis with IgM polyclonal mouse antibodies against SP-A proteins (Millipore MAB3270) and rabbit $\alpha$-mouse HRP-conjugated antibody (BD Pharmigen), as primary and secondary antibodies, respectively. A signal was developed using the ECL kit (Thermo Scientific).

To determine whether the degradation of SP-A by ScpA is time dependent, the protein was incubated in presence of $50 \mathrm{nM} \mathrm{ScpA}$ for $180 \mathrm{~min}$ at $37^{\circ} \mathrm{C}$, and after $12-, 30-, 45-, 60-, 90-, 120$ - and 180 min samples were withdrawn into the SDS-PAGE sample buffer and immediately boiled to stop the reaction. Analysis with Western blot was carried out as described above.

Degradation of SP-A in Bronchoalveolar Lavage in Presence of $S$. aureus Proteases

S. aureus (strains LAC, Newman and 8325-4) were cultured overnight in liquid media, supplemented with casein (5\%) and $\beta$ glycerophosphate $\left(5 \mathrm{~g} \cdot \mathrm{l}^{-1}\right)$. Bacteria were pelleted $(4,000 \mathrm{~g}, 20 \mathrm{~min})$ and supernatants were tested for their enzymatic activity.

Human bronchoalveolar lavage fluid (BALF) was obtained from human lungs rejected from the lung transplant program of the Silesian Center for Heart Diseases. Briefly, conductive airways were perfused with buffered solution (5 mM Tris, $\mathrm{pH} 7.4$, $150 \mathrm{~mm} \mathrm{NaCl}$ ). Samples were cleared by centrifugation, aliquoted and frozen at $-80^{\circ} \mathrm{C}$. In order to analyze the degradation of SP-A in BALF, $35 \mu$ l of BALF was mixed with $15 \mu$ l of bacterial culture supernatants and incubated for $6 \mathrm{~h}$ at $37^{\circ} \mathrm{C}$. As a control, $35 \mu \mathrm{l}$ of BALF was incubated with $15 \mu$ l of media. The reaction was stopped by addition of $15 \mu$ l of SDS-PAGE sample buffer $(4 \%$ SDS, 60\% glycerol, $0.3 \mathrm{M}$ Tris, 0.01\% Coomassie Brilliant Blue G-250, $50 \mathrm{~mm}$ DTT) and by boiling $\left(5 \mathrm{~min}, 99^{\circ} \mathrm{C}\right)$. Proteins were separated by SDS-PAGE electrophoresis in the Schagger-von Jagow system. Subsequently, samples were transferred onto the PVDF $\mathrm{P}^{\mathrm{SQ}}$ membrane (Millipore) for Western blot analysis of the SP-A protein. The membrane was blocked in 3\% skimmed milk (Fluka) at $4^{\circ} \mathrm{C}$ overnight and a signal was developed as described above.

\section{Aggregation Assay}

Salmonella spp. was cultured overnight in Luria broth media. Bacteria were pelleted by centrifugation $(4,000 \mathrm{~g}, 20 \mathrm{~min})$ and washed three times with sterile $1 \times$ PBS. A bacteria cell pellet was re-suspended in sterile $1 \times \mathrm{PBS}$ to reach final $\mathrm{OD}_{660}$ of 1 . SP-A protein was added to the suspension to reach the final concentration of $7.5 \mu \mathrm{g} \cdot \mathrm{ml}^{-1}$. The suspension was incubated at $37^{\circ} \mathrm{C}$ and the bacterial aggregation was assessed by means of sedimentation rate, employing the optical density measurements $(\lambda=660 \mathrm{~nm})$ every $15 \mathrm{~min}$ for $1 \mathrm{~h}$.

\section{Adhesion Assay}

A549 cells were seeded on 24-well plates $48 \mathrm{~h}$ prior to the experiment in order to reach full confluency. On the day of the experiment cells were washed three times with sterile $1 \times$ PBS and cooled down on ice. The Newman $S$. aureus strain was cultured in TSB (Sigma-Aldrich) overnight. The bacteria were washed three times with $1 \times$ PBS and re-suspended in fresh D-MEM media to reach the final concentration of $10^{6} \mathrm{cfu} \cdot \mathrm{ml}^{-1}$. The suspension was further incubated for $30 \mathrm{~min}$ at $4^{\circ} \mathrm{C}$ with SP-A $(25 \mu \mathrm{g}$ $\left.\mathrm{ml}^{-1}\right)$, but beforehand it was incubated with ScpA (50 nM) or with control buffer.

Staphylococcus aureus Proteases Degrade Lung Surfactant Protein A
S. aureus pre-incubated with SP-A protein (treated or untreated with staphopains) or control media was transferred onto A549 cells and incubated for $60 \mathrm{~min}$ at $4^{\circ} \mathrm{C}$. After that time the bacteria suspension was removed and cells were washed three times with pre-cooled sterile $1 \times$ PBS. The cells and bacteria were detached from the plate surface with $0.5 \times$ trypsin-EDTA solution (PAA) at room temperature and serial dilutions were seeded onto tryptic soy agar plates.

\section{Phagocytosis of S. aureus by Human Neutrophils}

$S$. aureus was cultured in TSB media (Sigma-Aldrich) overnight. After that the bacteria were centrifuged and washed three times with $50 \mathrm{ml}$ of $1 \times$ PBS. Pelleted bacteria were further resuspended in $2 \mathrm{ml}$ of $1 \times$ PBS and the optical density of bacterial cells was assessed $(\lambda=600 \mathrm{~nm})$. Cell count (cfu) was estimated based on previously developed standard curves and bacterial concentration was adjusted to $10^{9} \mathrm{cfu} \cdot \mathrm{ml}^{-1}$. To enable analysis of phagocytosis by flow cytometry, bacteria were incubated for $1 \mathrm{~h}$ at $37^{\circ} \mathrm{C}$ in $1 \times \mathrm{PBS}$ containing $0.1 \%$ of fluorescein isothiocyanate (FITC; Sigma-Aldrich). Non-bound FITC was washed out with $1 \times$ PBS in order to reduce the background staining. Labeled bacteria were further incubated with the SP-A protein $\left(25 \mu \mathrm{g} \cdot \mathrm{ml}^{-1}\right)$ for $45 \mathrm{~min}$ at $37^{\circ} \mathrm{C}$ in $5-\mathrm{ml}$ round-bottom polystyrene tubes (Becton Dickinson). After the incubation, $25 \mu \mathrm{l}$ of $S$. aureus $\left(10^{9}\right.$ $\left.\mathrm{cfu} \cdot \mathrm{ml}^{-1}\right)$ or control media was mixed with the $250 \mu \mathrm{l}$ of neutrophil suspension $\left(5 \times 10^{5} \mathrm{cells} \cdot \mathrm{ml}^{-1}\right)$ and incubated at $37^{\circ} \mathrm{C}$ for 60 min. Incubation was stopped by addition of $1 \mathrm{ml}$ of ice-cold $1 \times$ PBS supplemented with BSA (0.1\%). Cells were centrifuged $(110 \mathrm{~g}$, $5 \mathrm{~min}$ ) and washed with $1 \times$ PBS to separate unbound bacteria. Eventually, cells were re-suspended in $1 \times$ PBS supplemented with BSA $(0.1 \%)$. To exclude adherent but not internalized $S$. aureus from analysis, trypan blue was used as previously described [5]. FACS analysis was conducted on a FACScan machine (Becton Dickinson).

\section{Statistical Analysis}

All experiments were repeated at least three times and results are expressed as mean \pm SD. To determine the significance of obtained results, a comparison between groups was made using Student's t test. $\mathrm{p}$ values $<0.05$ were considered significant.

\section{Results}

Proteolytic Cleavage of SP-A by S. aureus

Extracellular Proteases

This study assessed the ability of extracellular proteases of S. aureus to degrade SP-A and inactivate antimicrobial activities of this protein. To this end we have first incubated SP-A with various concentrations of $S$. aureus proteases (ScpA, staphopain B, V8 protease and aureolysin), and analyzed the SP-A protein degradation by SDSPAGE.

The results clearly showed that SP-A was cleaved efficiently only by ScpA. Importantly, the ScpA concentration sufficient for total degradation of the SP-A protein 




Fig. 1. Analysis of SP-A protein processing by $S$. aureus enzymes. SDS-PAGE (a) and Western blot (b) analysis of protease-mediated SP-A degradation $\left(90 \mathrm{~min}, 37^{\circ} \mathrm{C}\right)$. Multiple bands visible on the Western blot and SDS-PAGE result from the fact that the SP-A protein forms multimeric complexes stable enough to survive the denaturing conditions. Discrepancy in intensity of bands between the SDS-PAGE gels and Western blots results from differ-

ences in antibody affinity towards particular multimeric SP-A forms and cleavage products. Names presented on the left side of the figure denote the enzyme used. Under each panel information on presence/absence of SP-A and concentration of the enzyme is given. Additional visible bands represent monomers and multimers of the SP-A protein. The results shown are representative of at least four independent experiments. 
Fig. 2. Time-dependent degradation of SP-A protein by $S$. aureus ScpA. SP-A protein was incubated with ScpA (a) or with a control buffer (b), as described in the Methods section. Information on presence/absence of SP-A and ScpA in each well is denoted beneath the panel. Additionally, visible bands represent monomers and multimers of the SP-A protein. The lane containing SP-A not treated with ScpA is provided in the right panel. The results shown are representative of at least three independent experiments.

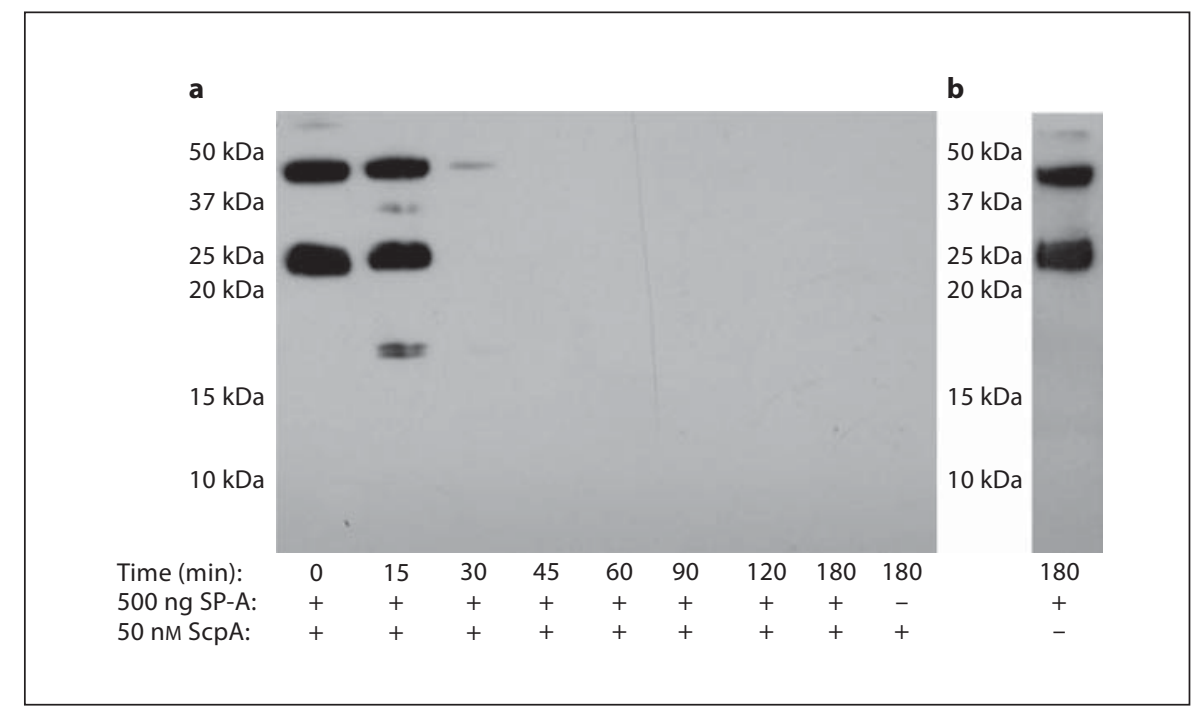

was in the nanomolar range $<50 \mathrm{nM}$. Incubation with staphopain B only resulted in partial cleavage of the protein at high enzyme concentrations, thereby reducing its possible in vivo function. No cleavage of SP-A was observed during incubation with V8 protease and aureoly$\sin$ (fig. 1) even at high protease concentrations and with an extended incubation time. The complete degradation of the SP-A protein by ScpA was visible after $45 \mathrm{~min}$ of incubation (fig. 2).

The ability of $S$. aureus proteases to specifically degrade SP-A protein was also assessed in an ex vivo system to confirm that the observed effect was not a result of structural alteration associated with protein purification procedure, or the storage and reaction conditions. Briefly, freshly collected BALF was incubated with supernatants from overnight cultures of various $S$. aureus strains, including LAC, Newman and 8325-4. Western blot analysis clearly showed that the SP-A found in human BALF was degraded after incubation with $S$. aureus bacterial supernatants (fig. 3).

\section{Proteolytic Cleavage of Surfactant Proteins Decreases SP-A-Mediated Bacterial Aggregation}

$S$. aureus lung infections have frequently been found to be coincident with infections by Gram-negative bacteria [40-44]. This suggests that SP-A degradation by ScpA may affect the clearance of other pathogens during polymicrobial pneumonia. A previously described model, based on Salmonella spp., was employed to test whether the ScpA-mediated degradation of SP-A affected this surfactant protein activity toward Gram-negative bacteria.

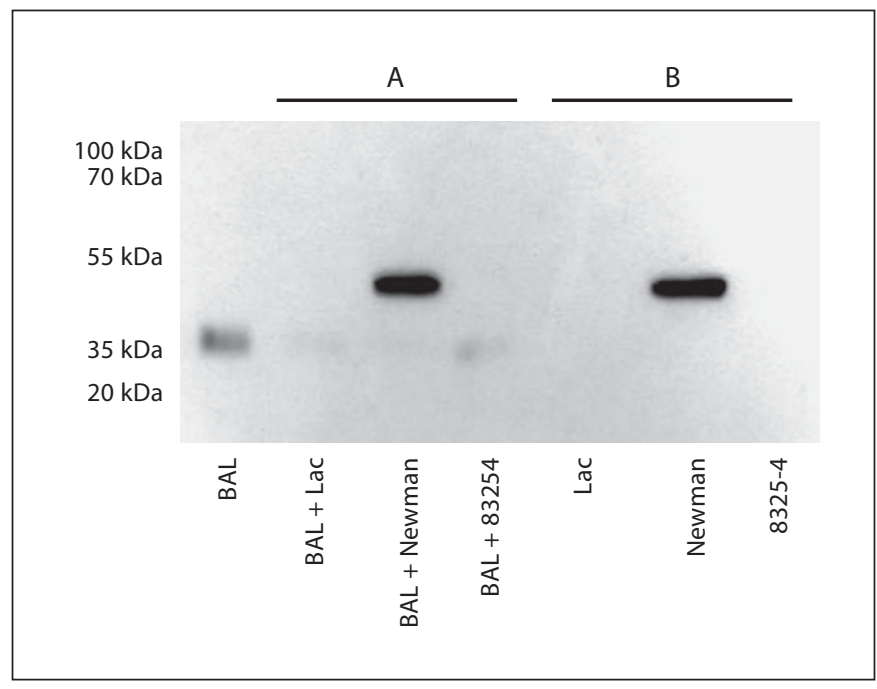

Fig. 3. Western blot analysis of SP-A degradation in BALF in the presence of $S$. aureus culture supernatants. BALF was incubated with supernatants from cultures of $S$. aureus strains LAC, 8325-4 and Newman as described in the Methods (part A). As controls, bacterial supernatants are also included (part B). The distinct band in the lane corresponding to the $S$. aureus Newman strain represents staphylococcal protein $\mathrm{A}$. The results shown are representative of at least three independent experiments.

Incubation of Salmonella spp. in the presence of the SP-A protein resulted in the rapid sedimentation of bacterial aggregates. However, this effect was severely reduced if the SP-A protein was pre-incubated with $S$. aureus ScpA protease (fig. 4). An assay using a specific synthetic cys- 
Fig. 4. Decrease in Gram-negative bacteria aggregation following SP-A incubation with ScpA. Human SP-A pre-incubated with ScpA was added to the Salmonella spp. culture. Change of absorbance due to the bacterial clamping/sedimentation was monitored. Results are presented as the percent change in the optical density at $\lambda=660 \mathrm{~nm}$ for the average values from three independent experiments. Buffer denotes the reaction buffer. E64 and SAF (staphostatin A) denote universal inhibitor of papain-like cysteine proteases and the proteinaceous, ScpA-specific inhibitor, respectively.

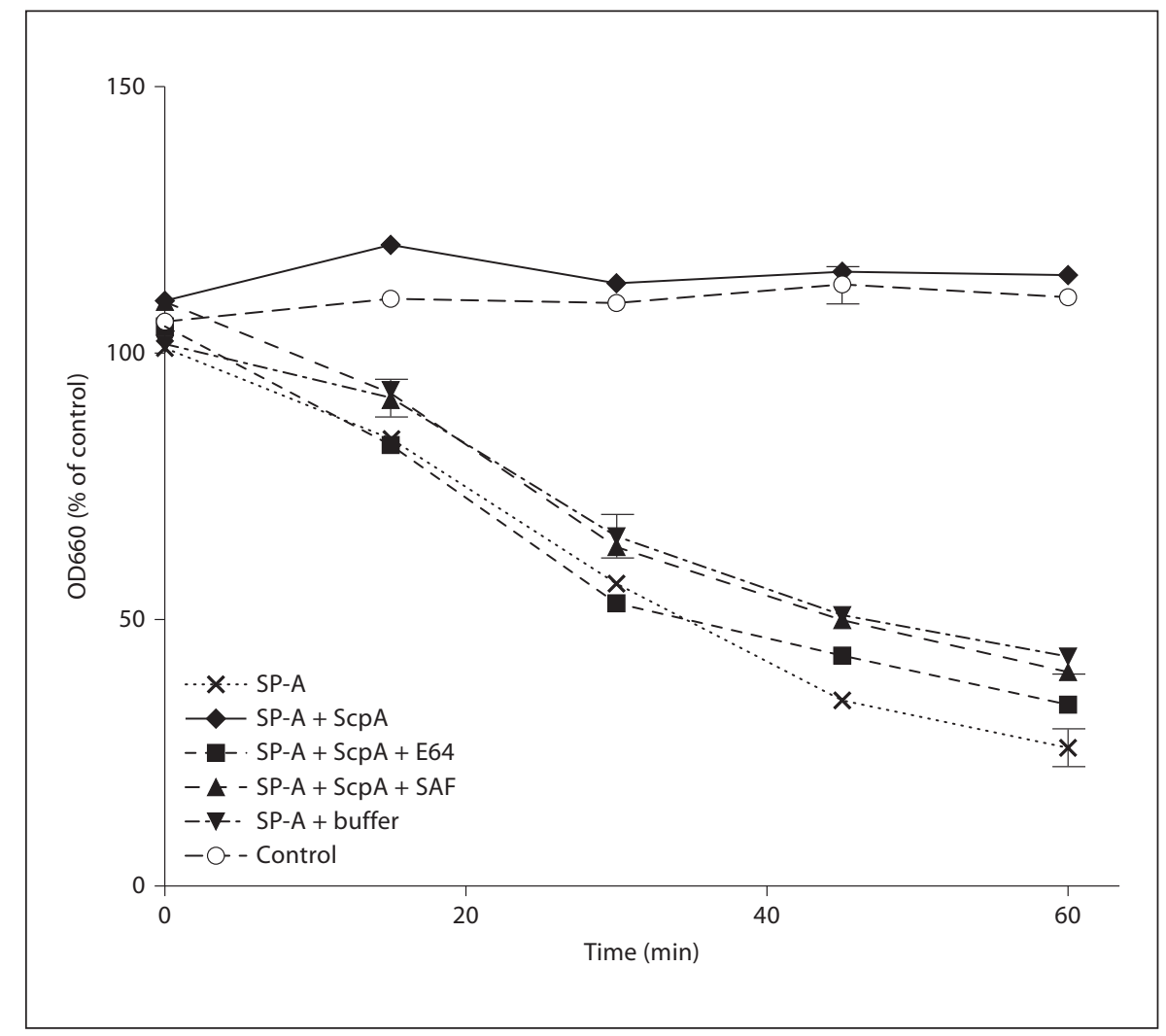

teine protease inhibitor (E64) and a natural ScpA inhibitor (staphostatin A) was conducted to determine whether the observed effect was the sole result of staphopain-mediated cleavage. The results suggested a direct link between the proteolytic activity of ScpA and the loss of function of the SP-A protein.

Proteolytic Processing of Surfactant Proteins Increases Adherence of S. aureus to Epithelial Cells

$S$. aureus binds to eukaryotic cells and it is possible that surfactant proteins may interfere with bacterial adherence to the epithelium, hindering their ability to colonize the respiratory tract [45]. This study analyzed the effect of the SP-A protein on the ability of $S$. aureus to adhere to A549 cells (ATCC CCL-185; a human lung carcinomaderived cell line). SP-A concentrations up to $5 \mu \mathrm{g} \cdot \mathrm{ml}^{-1} \mathrm{did}$ not affect the adherence of $S$. aureus to epithelial cells [46]; therefore, in this study we tested SP-A activity at higher concentrations, but still well below the physiological range $\left(50-100 \mu \mathrm{g} \cdot \mathrm{ml}^{-1}\right)$ of this protein concentration in the lungs. Already at $25 \mu \mathrm{g} \mathrm{ml}^{-1}$ SP-A decreased bacterial staphylococci adherence to the A549 cell monolayer by $\sim 40 \%$. Pre-incubation of SP-A with ScpA impeded this process and the number of bacteria attached to eukaryotic cells was restored to $>80 \%$ in relation to the positive control (fig. 5). This experiment clearly shows that ScpA may influence not only the direct effect of SP-A on bacteria, but also its interaction with host cells. Considering the importance of such findings, the subsequent analysis was designed to evaluate the ability of ScpA to impair the welldescribed role of SP-A in innate immunity, specifically pathogen phagocytosis by neutrophils.

\section{Proteolytic Processing of Surfactant Proteins Impairs} Bacterial Phagocytocis by Neutrophils

SP-A protein mediates bacterial phagocytosis by neutrophils $[5,23]$. Flow cytometry was used to confirm this and it was found that the ratio of neutrophils actively binding and internalizing $S$. aureus bacteria was drastically increased in the presence of SP-A (fig. 6). However, the pre-incubation of SP-A with ScpA resulted in the loss of the ability to enhance phagocytosis (fig. 1), as shown by the change in the ratio between neutrophils which internalized FITC-labeled S. aureus and the whole neutrophil population. ScpA totally abrogated the effect of SP-A on bacteria engulfment as revealed by restoration of the 


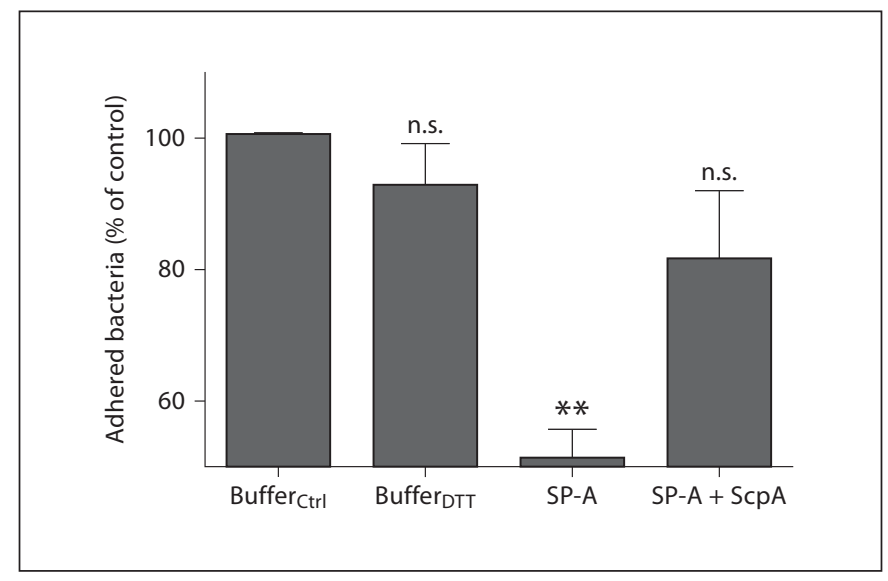

Fig. 5. Increase in S. aureus adherence to A 549 cells following SP-A incubation with ScpA. S. aureus adherence to human epithelial cell line was assessed as described in the Methods section. Bacteria incubated with SP-A, SP-A/ScpA, with reaction buffer without (Buffer $\left.\mathrm{Ctrl}_{\mathrm{C}}\right)$ and with reducing agents $\left(\right.$ Buffer $\left._{\mathrm{DTT}}\right)$ were inoculated onto the cell monolayer. Following the incubation and removal of unattached bacteria, adherent bacteria were scored. Data are presented as percent change in the number of adherent bacteria, as compared to the sample incubated with buffer without the reducing agents $\left(\right.$ Buffer $\left._{\mathrm{Ctrl}}\right)$. The results shown are average values from four independent experiments. The statistical significance of differences in $S$. aureus adherence to eukaryotic cells when compared with a control is indicated: ${ }^{* *} \mathrm{p}<0.005$. n.s. $=$ Not significant.

neutrophil phagocytosis efficiency to the control level. Clearly, ScpA had no effect on the basal level of S. aureus of clearance by neutrophil. This observation indicates that staphylococcal protease targeted exclusively phagocytosis dependent on the SP-A-opsonizing activity.

\section{Discussion}

Three major catalytic classes of $S$. aureus extracellular proteases (i.e. metallo-, serine and cysteine proteases [47]) exert a variety of virulence-related functions. These include tissue degradation [31, 32], effect on the host immune defense [33], interference with endogenous host enzymes [34] and the facilitation of bacterial dissemination $[35,36]$. Here we show that degradation of SP-A by staphylococcal proteases may hamper bacterial clearance and facilitate the colonization of the human respiratory tract. SP-A interacts with a variety of bacteria and enhances pathogen uptake by phagocytic cells $[5,48,49]$. Human SP-A was shown to stimulate the serum-independent phagocytosis of $S$. aureus by alveolar macrophages and neutrophils $[5,23]$. Furthermore, SP-A assists $S$. aureus

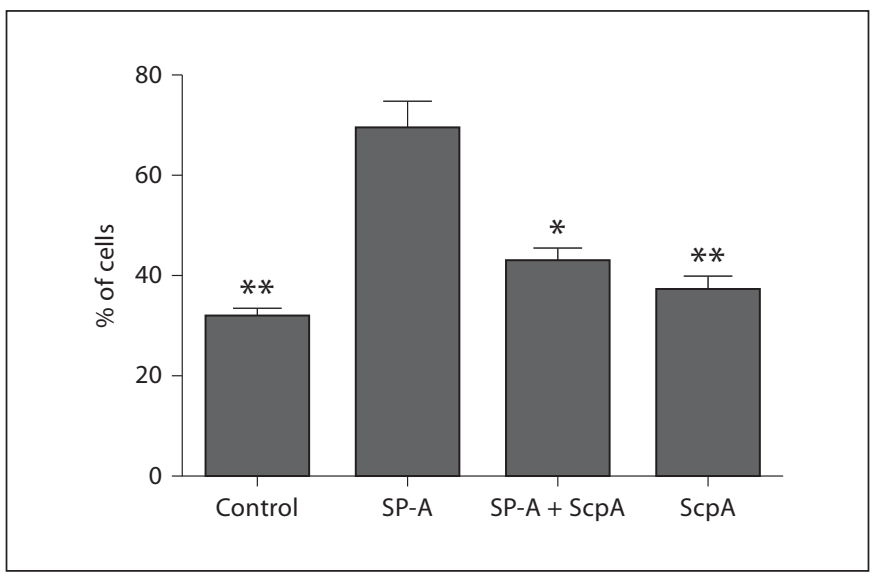

Fig. 6. Decrease in S. aureus phagocytosis by neutrophils after SP-A incubation with ScpA. FITC-labeled bacteria pre-incubated with SP-A, SP-A plus ScpA or ScpA alone were incubated with human neutrophils. Subsequently, bacteria that were not bound were removed, fluorescence derived from non-internalized bacteria was quenched using trypan blue and cells were analyzed by flow cytometry. Results shown are average values from three independent experiments and represent percentage of cells that internalized $S$. aureus bacteria. The statistical significance of differences in $S$. aureus adherence to eukaryotic cells when compared with a control is indicated: ${ }^{*} \mathrm{p}<0.05 ;{ }^{* *} \mathrm{p}<0.005$.

phagocytosis by monocytes via its interaction with the C1q receptor on these cells [11] and the SP-R210 and SR-A receptors on macrophages [23]. The SP-A concentration in the BALF of healthy individuals was found to be high, reaching a concentration of $>10 \mu \mathrm{g} \cdot \mathrm{ml}^{-1}$, thereby indicating even higher concentrations in surfactant fluid. Thus, in the current study SP-A was used at concentrations in the range of $7.5-25 \mu \mathrm{g} \cdot \mathrm{ml}^{-1}$. Similar concentrations were tested in previous reports $[5,50,51]$.

Previous studies of the interaction between bacteria and the SP-A protein found that $P$. aeruginosa elastase can efficiently degrade SP-A. An analysis of BALF from lung transplant patients with cystic fibrosis revealed the presence of SP-A fragments resulting from protease-mediated degradation [51]. Careful analysis of our experimental data revealed that a similar phenomenon is observed for $S$. aureus with ScpA being the most efficient protease in SP-A molecule degradation. ScpA-mediated cleavage of SP-A resulted in a decrease or complete inhibition of SP-A biological activity, including the promotion of $S$. aureus phagocytosis by neutrophils, aggregation of Gram-negative bacteria and bacterial adherence to epithelial cells. Experimental analysis of complete BALF from human 
lungs also showed that SP-A degradation by ScpA was not hampered by protease inhibitors or competing substrates that may be present in vivo. This experiment also showed that the amount of proteases secreted by clinical strains is sufficient to mediate cleavage. To further study the relevance of the process, an effort was made to determine whether staphopains are present in BALF from patients with staphylococcal respiratory tract infections. Immunoprecipitation followed by mass spectrometry SRM analysis failed to reveal the presence of ScpA in BALF samples (data not shown), which can be due to strain-specific variants of the enzyme primary structure. Unfortunately, no $S$. aureus strains were available to verify this possibility, which will be explored in future studies.

The results of in vivo studies investigating the role of ScpA in S. aureus infection are rather inconclusive [52]. Nevertheless, several in vitro studies showed that both staphopains are involved in the modulation of the infectious outcome $[29,37,38,53,54]$. The discrepancy between in vivo and in vitro models can be readily explained because in contrast to human serum, mouse serum inhibits staphopain activity. Both enzymes were shown to efficiently degrade human endogenous protease inhibitors ( $\alpha$-1-antitrypsin and $\alpha$-1-antichymotrypsin) that are essential for the regulation of human serine protease activities $[34,55]$ and are important in protection of human lungs against uncontrolled proteolysis. Therefore, the deregulation of proteolytic homeostasis will most likely lead to excessive connective tissue degradation. This, together with the staphopain-mediated hampering of SP-A phagocytosis-promoting and -opsonizing functions may constitute ScpA as main virulence factors in the staphylococcal diseases of the lower respiratory tract. Overall, this study showed that the S. aureus protease ScpA functions as an important virulence factor that efficiently degrades SP-A, which is one of the key elements of lung innate immunity. Multiple models showed that degradation by ScpA results in the abolition of SP-A biological activity. The function of SP-A protein is described in detail both in vivo and in vitro [2, 18-23], so it may be assumed that the process observed is of clinical relevance.

Clinical observations of SP-A levels during bacterial pneumonia are inconsistent, because some authors have reported a rapid decrease in SP-A levels [49] whereas others found increased protein levels during infection [56]. This discrepancy is probably attributable to the methodology applied by researchers, particularly whether the test employed detected the SP-A fragments or only the complete protein. In this context, more work is required to determine the in vivo role of SP-A proteolytic digestion in the development of $S$. aureus-related pneumonia.

\section{Acknowledgements}

The authors thank Prof. Jo Rae Wright, Duke University Medical Center, Durham, N.C., USA, for kindly providing the SP-A protein. Further, the authors thank Katarzyna Falkowski and Laura Sasiadek for reading the manuscript and suggesting useful changes in style and organization. This work was supported by grants from the Foundation for Polish Science (TEAM project DPS/424-329/10) (J.P., K. Pyrc, K. Plaza and T.K.), National Science Centre, Poland (2011/01/D/NZ6/00269) (K. Pyrc), Ministry of Science and Higher Education, Poland (Iuventus Plus grant IP2011 044371, IP2011 022171 and grants 0095/B/P01/2009/37 and 1642/B/P01/2008/35) (K. Pyrc, T.K. and J.P.), the Jagiellonian University statutory funds DS/9/WBBiB (J.P. and K. Pyrc), and grants from the National Institutes of Health, USA (DE 09761) (J.P.). The Faculty of Biochemistry, Biophysics and Biotechnology of the Jagiellonian University is a beneficiary of the structural funds from the European Union (grant No.: POIG.02.01.00-12064/08 - 'molecular biotechnology for health'). The funders had no role in study design, data collection and analysis, decision to publish or preparation of the manuscript.

\section{Disclosure Statement}

The authors declare that they have no conflict of interests.
References
King RJ, Clements JA: Surface active materials from dog lung. I. Method of isolation. Am J Physiol 1972;223:707-714.

2 LeVine AM, Kurak KE, Wright JR, Watford WT, Bruno MD, Ross GF, Whitsett JA, Korfhagen TR: Surfactant protein-A binds group B streptococcus enhancing phagocytosis and clearance from lungs of surfactant protein-A-deficient mice. Am J Respir Cell Mol Biol 1999;20:279-286.
3 Crouch E, Hartshorn K, Ofek I: Collectins and pulmonary innate immunity. Immunol Rev 2000;173:52-65.

-4 Shepherd VL: Distinct roles for lung collectins in pulmonary host defense. Am J Respir Cell Mol Biol 2002;26:257-260.

5 Hartshorn KL, Crouch E, White MR, Colamussi ML, Kakkanatt A, Tauber B, Shepherd V, Sastry KN: Pulmonary surfactant proteins $A$ and D enhance neutrophil uptake of bacteria. Am J Physiol 1998;274:L958-L969. 
-6 Sano H, Sohma H, Muta T, Nomura S, Voelker DR, Kuroki Y: Pulmonary surfactant protein A modulates the cellular response to smooth and rough lipopolysaccharides by interaction with CD14. J Immunol 1999;163: 387-395.

7 Borron P, McIntosh JC, Korfhagen TR, Whitsett JA, Taylor J, Wright JR: Surfactantassociated protein A inhibits LPS-induced cytokine and nitric oxide production in vivo. Am J Physiol Lung Cell Mol Physiol 2000; 278:L840-L847.

-8 Murakami S, Iwaki D, Mitsuzawa H, Sano H, Takahashi H, Voelker DR, Akino T, Kuroki Y: Surfactant protein A inhibits peptidoglycan-induced tumor necrosis factor- $\alpha$ secretion in U937 cells and alveolar macrophages by direct interaction with Toll-like receptor 2. J Biol Chem 2002;277:6830-6837.

-9 Hickman-Davis J, Gibbs-Erwin J, Lindsey JR, Matalon S: Surfactant protein A mediates mycoplasmacidal activity of alveolar macrophages by production of peroxynitrite. Proc Natl Acad Sci USA 1999;96:4953-4958.

10 Whitsett JA, Weaver TE: Hydrophobic surfactant proteins in lung function and disease. N Engl J Med 2002;347:2141-2148.

-11 Geertsma MF, Nibbering PH, Haagsman HP, Daha MR, van Furth R: Binding of surfactant protein $\mathrm{A}$ to $\mathrm{Clq}$ receptors mediates phagocytosis of Staphylococcus aureus by monocytes. Am J Physiol 1994;267:L578L584.

12 Kabha K, Schmegner J, Keisari Y, Parolis H, Schlepper-Schaeffer J, Ofek I: SP-A enhances phagocytosis of Klebsiella by interaction with capsular polysaccharides and alveolar macrophages. Am J Physiol 1997;272:L344L352.

13 Weikert LF, Edwards K, Chroneos ZC, Hager C, Hoffman L, Shepherd VL: SP-A enhances uptake of bacillus Calmette-Guérin by macrophages through a specific SP-A receptor. Am J Physiol 1997;272:L989-L995.

-14 Canadas O, Garcia-Verdugo I, Keough KM, Casals C: SP-A permeabilizes lipopolysaccharide membranes by forming protein aggregates that extract lipids from the membrane. Biophys J 2008;95:3287-3294.

15 Garcia-Verdugo I, Canadas O, Taneva SG, Keough KM, Casals C: Surfactant protein a forms extensive lattice-like structures on 1,2-dipalmitoylphosphatidylcholine/roughlipopolysaccharide-mixed monolayers. Biophys J 2007;93:3529-3540.

-16 Uemura T, Sano H, Katoh T, Nishitani C, Mitsuzawa H, Shimizu T, Kuroki Y: Surfactant protein A without the interruption of Gly-X-Y repeats loses a kink of oligomeric structure and exhibits impaired phospholipid liposome aggregation ability. Biochemistry 2006;45:14543-14551.
17 Kuronuma K, Sano H, Kato K, Kudo K, Hyakushima N, Yokota S, Takahashi H, Fujii N, Suzuki H, Kodama T, Abe S, Kuroki Y: Pulmonary surfactant protein A augments the phagocytosis of Streptococcus pneumoniae by alveolar macrophages through a casein kinase 2-dependent increase of cell surface localization of scavenger receptor A. J Biol Chem 2004;279:21421-21430.

-18 LeVine AM, Bruno MD, Huelsman KM, Ross GF, Whitsett JA, Korfhagen TR: Surfactant protein A-deficient mice are susceptible to group B streptococcal infection. J Immunol 1997; 158:4336-4340.

19 LeVine AM, Gwozdz J, Stark J, Bruno M, Whitsett J, Korfhagen T: Surfactant proteinA enhances respiratory syncytial virus clearance in vivo. J Clin Invest 1999;103:10151021.

20 LeVine AM, Kurak KE, Bruno MD, Stark JM, Whitsett JA, Korfhagen TR: Surfactant protein-A-deficient mice are susceptible to Pseudomonas aeruginosa infection. Am J Respir Cell Mol Biol 1998;19:700-708.

21 LeVine AM, Whitsett JA, Gwozdz JA, Richardson TR, Fisher JH, Burhans MS, Korfhagen TR: Distinct effects of surfactant protein $\mathrm{A}$ or D deficiency during bacterial infection on the lung. J Immunol 2000;165:3934-3940.

22 LeVine AM, Whitsett JA, Hartshorn KL, Crouch EC, Korfhagen TR: Surfactant protein $\mathrm{D}$ enhances clearance of influenza A virus from the lung in vivo. J Immunol 2001; 167:5868-5873.

23 Sever-Chroneos Z, Krupa A, Davis J, Hasan $\mathrm{M}$, Yang CH, Szeliga J, Herrmann M, Hussain M, Geisbrecht BV, Kobzik L, Chroneos ZC: Surfactant protein A (SP-A)-mediated clearance of Staphylococcus aureus involves binding of SP-A to the staphylococcal adhesin Eap and the macrophage receptors SP-A receptor 210 and scavenger receptor class $\mathrm{A}$. J Biol Chem 2011;286:4854-4870.

24 van Belkum A, Verkaik NJ, de Vogel CP, Boelens HA, Verveer J, Nouwen JL, Verbrugh HA, Wertheim HF: Reclassification of Staphylococcus aureus nasal carriage types. J Infect Dis 2009;199:1820-1826.

25 Moet GJ, Jones RN, Biedenbach DJ, Stilwell MG, Fritsche TR: Contemporary causes of skin and soft tissue infections in North America, Latin America, and Europe: report from the sentry antimicrobial surveillance program (1998-2004). Diagn Microbiol Infect Dis 2007;57:7-13.

26 Dryden MS: Skin and soft tissue infection: microbiology and epidemiology. Int J Antimicrob Agents 2009;34(suppl 1):S2-S7.

27 Naber CK: Staphylococcus aureus bacteremia: epidemiology, pathophysiology, and management strategies. Clin Infect Dis 2009; 48(suppl 4):S231-S237.

28 Kantyka T, Shaw LN, Potempa J: Papain-like proteases of Staphylococcus aureus. Adv Exp Med Biol 2011;712:1-14.
9 Kulig P, Zabel BA, Dubin G, Allen SJ, Ohyama T, Potempa J, Handel TM, Butcher EC, Cichy J: Staphylococcus aureus-derived staphopain B, a potent cysteine protease activator of plasma chemerin. J Immunol 2007;178:3713-3720.

30 Sieprawska-Lupa M, Mydel P, Krawczyk K, Wojcik K, Puklo M, Lupa B, Suder P, Silberring J, Reed M, Pohl J, Shafer W, McAleese F, Foster T, Travis J, Potempa J: Degradation of human antimicrobial peptide LL-37 by Staphylococcus aureus-derived proteinases. Antimicrob Agents Chemother 2004;48: 4673-4679.

31 Potempa J, Dubin A, Korzus G, Travis J: Degradation of elastin by a cysteine proteinase from Staphylococcus aureus. J Biol Chem 1988;263:2664-2667.

-32 Cheng AG, DeDent AC, Schneewind O, Missiakas D: A play in four acts: Staphylococcus aureus abscess formation. Trends Microbiol 2011;19:225-232.

- 33 Laarman AJ, Ruyken M, Malone CL, van Strijp JA, Horswill AR, Rooijakkers SH: Staphylococcus aureus metalloprotease aureolysin cleaves complement $\mathrm{C} 3$ to mediate immune evasion. J Immunol 2011;186:64456453.

34 Potempa J, Watorek W, Travis J: The inactivation of human plasma alpha 1-proteinase inhibitor by proteinases from Staphylococcus aureus. J Biol Chem 1986;261:14330-14334.

35 McGavin MJ, Zahradka C, Rice K, Scott JE: Modification of the Staphylococcus aureus fibronectin binding phenotype by V8 protease. Infect Immun 1997;65:2621-2628.

36 McAleese FM, Walsh EJ, Sieprawska M, Potempa J, Foster TJ: Loss of clumping factor B fibrinogen binding activity by Staphylococcus aureus involves cessation of transcription, shedding and cleavage by metalloprotease. J Biol Chem 2001;276:29969-29978.

- 37 Smagur J, Guzik K, Bzowska M, Kuzak M, Zarebski M, Kantyka T, Walski M, Gajkowska B, Potempa J: Staphylococcal cysteine protease staphopain B ( $\mathrm{SspB}$ ) induces rapid engulfment of human neutrophils and monocytes by macrophages. Biol Chem 2009;390:361-371.

38 Smagur J, Guzik K, Magiera L, Bzowska M, Gruca M, Thogersen IB, Enghild JJ, Potempa $\mathrm{J}$ : A new pathway of staphylococcal pathogenesis: Apoptosis-like death induced by Staphopain B in human neutrophils and monocytes. J Innate Immun 2009;1:98-108.

39 Golonka E, Filipek R, Sabat A, Sinczak A, Potempa J: Genetic characterization of Staphopain genes in Staphylococcus aureus. Biol Chem 2004;385:1059-1067.

40 Pereira Gomes JC, Pedreira WL Jr, Araujo EM, Soriano FG, Negri EM, Antonangelo L, Tadeu Velasco I: Impact of BAL in the management of pneumonia with treatment failure: positivity of BAL culture under antibiotic therapy. Chest 2000;118:1739-1746. 
41 Fagon JY, Chastre J, Domart Y, Trouillet JL, Pierre J, Darne C, Gibert C: Nosocomial pneumonia in patients receiving continuous mechanical ventilation. Prospective analysis of 52 episodes with use of a protected specimen brush and quantitative culture techniques. Am Rev Respir Dis 1989;139:877884.

42 Mandell LA, Campbell GD Jr: Nosocomial pneumonia guidelines: an international perspective. Chest 1998;113:188S-193S.

43 Bartlett JG, O'Keefe P, Tally FP, Louie TJ, Gorbach SL: Bacteriology of hospital-acquired pneumonia. Arch Intern Med 1986; 146:868-871.

-44 Okada F, Ando Y, Honda K, Nakayama T, Ono A, Tanoue S, Maeda T, Mori H: Acute Klebsiella pneumoniae pneumonia alone and with concurrent infection: comparison of clinical and thin-section CT findings. Br J Radiol 2010;83:854-860.

45 Edwards JA, Groathouse NA, Boitano S: Bordetella bronchiseptica adherence to cilia is mediated by multiple adhesin factors and blocked by surfactant protein A. Infect Immun 2005;73:3618-3626.
6 Ferrara A, Dos Santos C, Lupi A: Effect of different antibacterial agents and surfactant protein-A (SP-A) on adherence of some respiratory pathogens to bronchial epithelial cells. Int J Antimicrob Agents 2001;17:401405.

47 Dubin G: Extracellular proteases of staphylococcus spp. Biol Chem 2002;383:10751086.

48 Ding J, Umstead TM, Floros J, Phelps DS: Factors affecting SP-A-mediated phagocytosis in human monocytic cell lines. Respir Med 2004;98:637-650.

49 Manz-Keinke H, Plattner H, SchlepperSchafer J: Lung surfactant protein A (SP-A) enhances serum-independent phagocytosis of bacteria by alveolar macrophages. Eur J Cell Biol 1992;57:95-100.

50 Balamugesh T, Kaur S, Majumdar S, Behera D: Surfactant protein-A levels in patients with acute respiratory distress syndrome. Indian J Med Res 2003;117:129-133.

51 Mariencheck WI, Alcorn JF, Palmer SM, Wright JR: Pseudomonas aeruginosa elastase degrades surfactant proteins A and D. Am J Respir Cell Mol Biol 2003;28:528-537.

52 Imamura T, Tanase S, Szmyd G, Kozik A, Travis J, Potempa J: Induction of vascular leakage through release of bradykinin and a novel kinin by cysteine proteinases from Staphylococcus aureus. J Exp Med 2005;201: 1669-1676.
53 Ohbayashi T, Irie A, Murakami Y, Nowak M, Potempa J, Nishimura Y, Shinohara M, Imamura T: Degradation of fibrinogen and collagen by staphopains, cysteine proteases released from Staphylococcus aureus. Microbiology 2011;157:786-792.

54 Vincents B, Onnerfjord P, Gruca M, Potempa J, Abrahamson M: Down-regulation of human extracellular cysteine protease inhibitors by the secreted staphylococcal cysteine proteases, staphopain A and B. Biol Chem 2007;388:437-446.

55 Rapala-Kozik M, Potempa J, Nelson D, Kozik A, Travis J: Comparative cleavage sites within the reactive-site loop of native and oxidized alpha1-proteinase inhibitor by selected bacterial proteinases. Biol Chem 1999; 380:1211-1216

56 Noah TL, Murphy PC, Alink JJ, Leigh MW, Hull WM, Stahlman MT, Whitsett JA: Bronchoalveolar lavage fluid surfactant protein$A$ and surfactant protein-D are inversely related to inflammation in early cystic fibrosis. Am J Respir Crit Care Med 2003;168:685691. 